\title{
Structural assessment of the tower of the University of Coimbra by modal identification
}

\author{
Eduardo Nuno Brito Santos Júlio*, Carlos Alberto da Silva Rebelo ${ }^{1}$, Daniel António Semblano Gouveia \\ Dias-da-Costa ${ }^{2}$ \\ Civil Engineering Department, Faculty of Sciences and Technology, University of Coimbra, Rua Luís Reis Santos (Polo II), 3030-788 Coimbra, Portugal
}

\section{A R T I C L E I N F O}

\section{Article history:}

Received 15 January 2008

Received in revised form

27 May 2008

Accepted 2 June 2008

Available online $\mathrm{xxxx}$

\section{Keywords:}

Tower

Inspection

Modal identification

Diagnosis

Finite element method

\begin{abstract}
A B S T R A C T
The University of Coimbra was founded in 1290. Erected between 1728 and 1733, the present Tower of the University is not only the symbol of the university, but the symbol of the city itself. A recent inspection of the tower, conducted to prepare restoration works, revealed some structural anomalies, including degradation of joints and cracking of stone blocks. In this paper we describe a study undertaken to assess rapidly the structural integrity of the tower, in order to minimize the delay of the previously planned non-structural intervention. A finite element model of the tower was built with ADINA software and calibrated with measured data obtained from ambient vibration, namely the mode shapes and the natural frequencies. Results point toward the probable non existence of structural problems. It was concluded that modal identification is a fast and reliable technique that can be used in-situ to establish the structural assessment of this type of construction.
\end{abstract}

(c) 2008 Elsevier Ltd. All rights reserved.

\section{Introduction}

The University of Coimbra was founded in 1290 by King D. Dinis in Lisbon, being one of the oldest universities in Europe. In 1308 the university was moved to Coimbra, a city with a long tradition of education and the capital of the Portuguese Kingdom until 1260. Afterwards, the university was moved between these two cities more than once until 1537, when king D. João III finaly settled the university in Coimbra at the "Alcáçova Real", the ancient royal palace.

During Portugal's great era of expansion, Portuguese navigators discovered many lands overseas. The countries where Portuguese is the official language, Angola, Brazil, Cape Verde, Guinea-Bissau, Mozambique, São Tomé, Príncipe and East Timor are the present testimony of the glorious past of the Portuguese Empire that included other possessions such as Goa, Daman and Diu in India, and Macau in China. Since the University of Coimbra was the only Portuguese university for many centuries, more precisely until the instauration of the republic in 1910, its influence in the worlds' history and culture is overwhelming.

\footnotetext{
* Corresponding author. Tel.: +351 239797 258; fax: +351 239797259.

E-mail addresses: ejulio@dec.uc.pt (E.N.B.S. Júlio), crebelo@dec.uc.pt (C.A. da Silva Rebelo), dcosta@dec.uc.pt (D.A.S.G. Dias-da-Costa).

1 Tel.: +351239797 209

2 Tel.: +351239797256.
}

Situated on the top of the highest hill of Coimbra, the university is the symbol of the city. The University Tower, although not being the most important construction, from a historical, cultural or architectural point of view, certainly is the element with highest iconographic presence, constituting the image of the university and the symbol of the city itself, due to its importance in the latter.

Recently, an inspection was undertaken to evaluate the state of conservation of the tower in order to prepare for restoration works. Some non-structural anomalies, such as colour changes because of biological colonization, were identified. However, other defects equally registered included degradation of joints and cracking of stone blocks. These led to the necessity of also performing a structural diagnosis.

This paper describes the study conducted to rapidly assess the structural integrity of the tower, in order to minimize the delay of the previously planned non-structural intervention.

\section{Description of the tower}

In 1545 Frei Diogo de Murça, Rector of the University of Coimbra, replaces the clock of the university and changes its location to be closer to the scholar site. He orders the heightening of the ancient cubic tower on the yard side, which sheltered the private stairs of the king, and the creation, on top of this, of the room needed to house the clock's mechanism and bell [4]. In $1561 \mathrm{a}$ new tower is built, close to the Norwest angle, in rubble stone with coursed stone masonry at the corners, designed by João de Ruão. 


\section{$A R T C L I E$ IN PRESS}

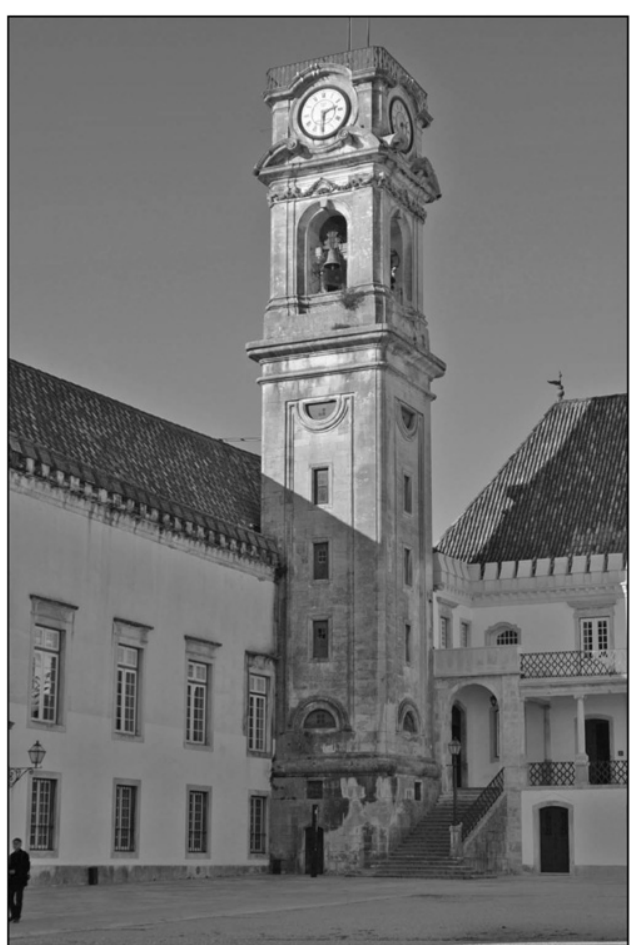

Fig. 1. Tower of the University of Coimbra.

Between 1728 and 1733, the present University Tower is erected, designed by António Canevari from the school of the architect Ludovice [4].

Fig. 1 shows a picture of the University Tower, seen from the interior of the "Paço das Escolas". The tower has a rectangular footprint and equal side views. From bottom to top, the tower presents: the base, the main body, the zone of the bells and the zone of the clock. The North façade is adjacent to the "Alcáçova" and the West façade intersects the building of the "Gerais" where the Law Faculty is still situated. Each façade presents: at the lower part, a quadrangular window of small dimensions, two semicircular windows on the base and on the top, and three doors between these; on the main body, a large opening with an arch where the bell is located and the clock. The outer walls are faced with masonry and the inner walls, of circular shape, are of ceramic bricks plastered and whitewashed. On the centre of the tower, also of circular geometry, there is another wall made of ceramic bricks plastered and whitewashed and, connecting both walls, limestone steps form a spiral staircase leading to the last window. At this level, a new spiral staircase begins through the Norwest pillar of the bell chamber up to the top of the tower.

\section{Description of the study performed}

\subsection{Objective and methodology}

The study described here was performed with the objective of rapidly assessing the need to consolidate and/or strengthen the University Tower. For this reason, soundings, NDT in-situ tests, static and dynamic tests, as well as monitoring, although giving reliable results [1-3], were excluded, at this phase, for being timeconsuming.

The methodology defined to reach the goal consisted of: (1) building a numerical model of the University Tower using the finite element method; (2) defining the localization of the measurement points and directions from the analysis of the vibration mode shapes of the numerical model; (3) identifying the mode shapes and frequencies, using the ambient vibration; and (4) calibrating the numerical model. After that, it is possible to simulate the structural behaviour of the tower, subjected to different combinations of static and dynamic loads, knowing that "it will never simulate all the complexity involved in the real phenomena" [6]. The analysis of these results allows evaluation of the need to consolidate and/or strengthen the tower.

\subsection{Finite element model}

The numerical model of the tower was built using the finite element program ADINA. The geometry of the structure was defined based on a photogrammetric survey, plans and sectional drawings (Fig. 2). By association of 2D drawings it was possible to generate a 3D model of the tower, in DXF format, which was transformed into the finite element model.

The finite element mesh was built using 4 node tetrahedra. Different mesh refinements were tested in order to minimize computation time, given an acceptable numerical error. As an example, three different meshes are presented in Fig. 3, considering $20 \mathrm{~cm}$, $30 \mathrm{~cm}$ and $60 \mathrm{~cm}$ side tetrahedra, which correspond to $59 \mathrm{~min}$; $1 \mathrm{~min}$ and $35 \mathrm{~s}$; and $7 \mathrm{~s}$ of computation time, respectively.

As support conditions, since the type and the state of conservation of the foundation are unknown, as well as the soil characteristics, it was decided to assume all displacements of the base nodes restrained. Due to the uncertainty relative to the characteristics and restraint level imposed on the tower by walls and slabs of the surrounding buildings, the horizontal displacements of common walls were considered restrained in the normal direction. Based on the measurements performed on site, this model was calibrated, as described above, it was found necessary to make several adjustments to the boundary conditions during this process.

Besides the type of finite elements selected, the refinement of the adopted mesh and the assumed support conditions, the structural behaviour of the model is also influenced by the material properties. As previously mentioned, the outer layer of the tower walls is of masonry and the inner layer is made of ceramic bricks. Tests to evaluate the mechanical characteristics of the stone blocks, mortar and ceramic bricks were not conducted. Soundings to quantify the dimensions of both wall layers were not conducted either. Therefore, the tower walls were assumed homogeneous in the analysis by taking an equivalent Young's modulus and an equivalent shear modulus. During the calibration process of the numerical model, the values initially adopted were successively corrected.

In Fig. 4 the first five vibration mode shapes and corresponding frequencies, obtained with the first finite element model, are presented.

\subsection{Modal identification}

The measurement of the dynamic behaviour of the tower was performed using a frequency analyser to record the signal from eight accelerometers (Fig. 5). Four of these were kept fixed as reference signals and the remaining four were moved between predefined positions and directions.

The modal identification was performed using techniques of modal extraction in the frequency domain (peak picking and frequency domain decomposition) implemented with ARTeMIS software. These techniques allow the estimation of not only the natural frequencies and modal damping but also each mode shape.

The measurement plan included two stages. In a preliminary stage, measurements were performed only at the level of the bells and the top terrace of the tower. This constituted a first approximation to be compared with the results of the initial finite element model, developed with ADINA software. Conclusions from 


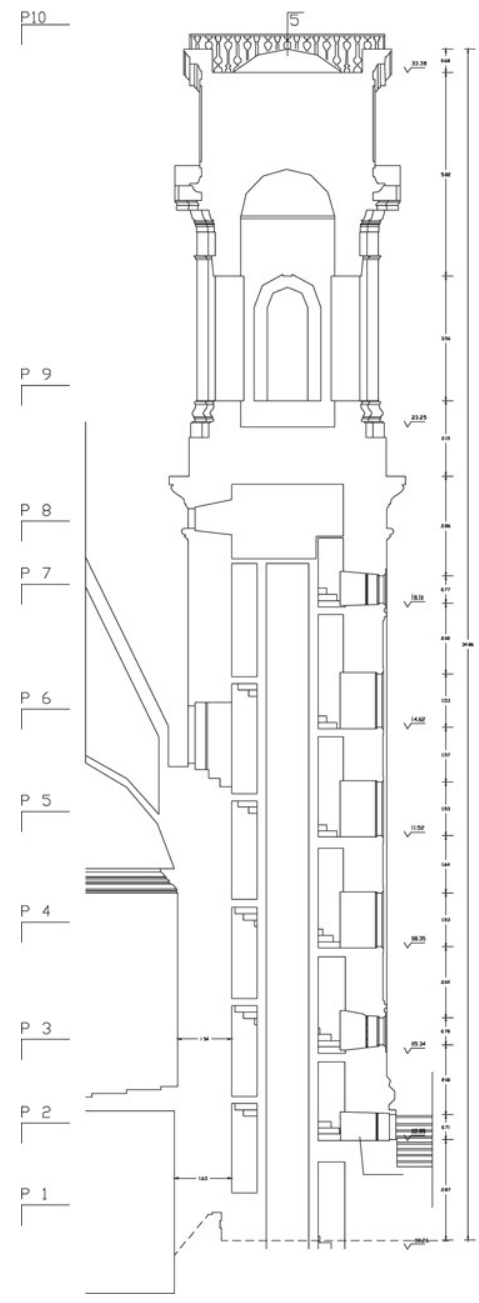

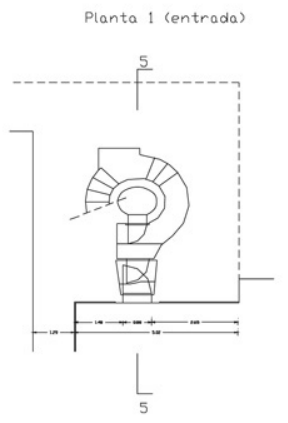
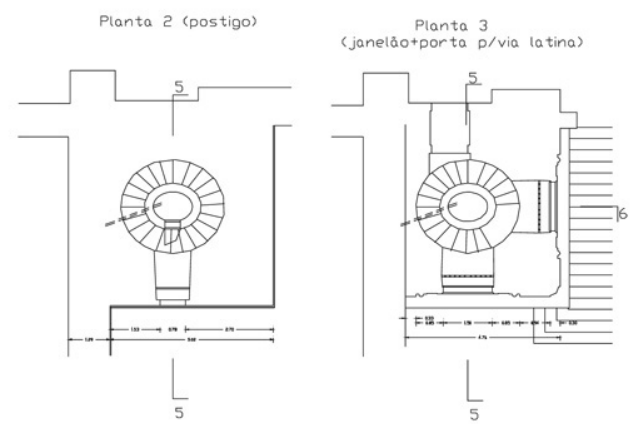

Planta $4\left(1^{\circ}\right.$ porta

Planta $5\left(2^{\circ}\right.$ porta $)$

Planta $6\left(3^{\circ}\right.$ porta $)$
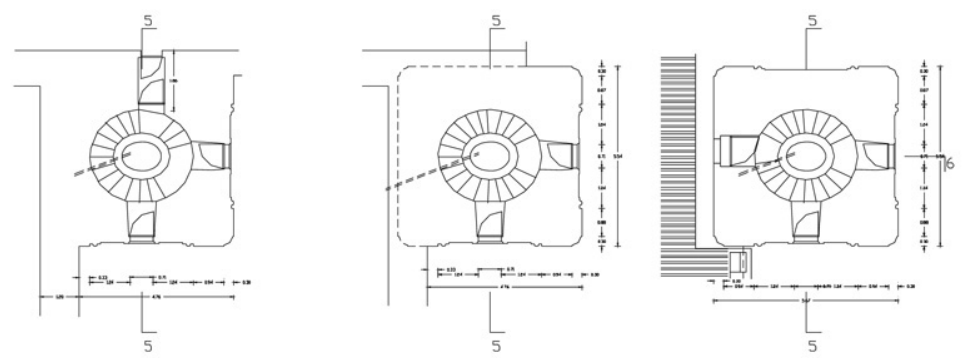

Planta 9 (sinos)

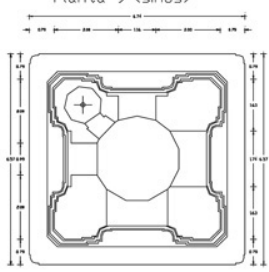

Planta 10 (cobertura)

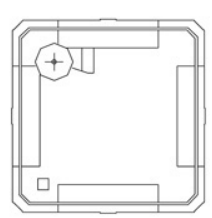

Planta 7 (2i janeloo)

Planta 8 (relógio)
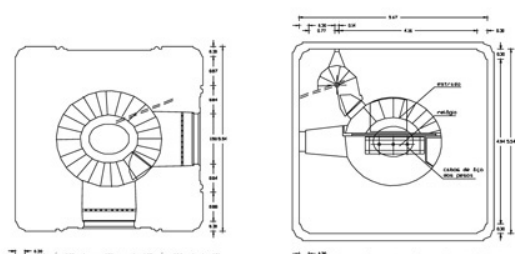

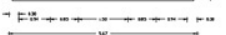

Fig. 2. Sectional drawings of the University Tower.

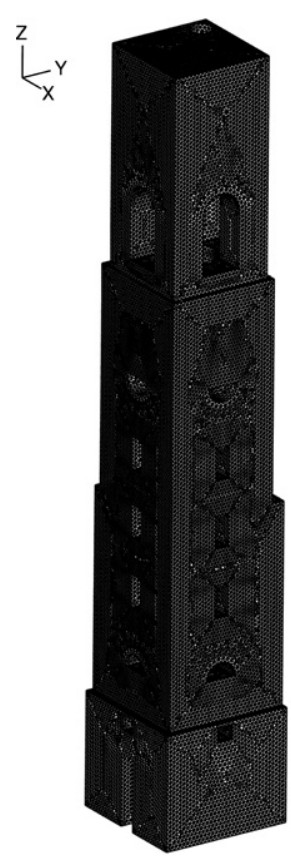

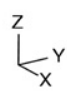
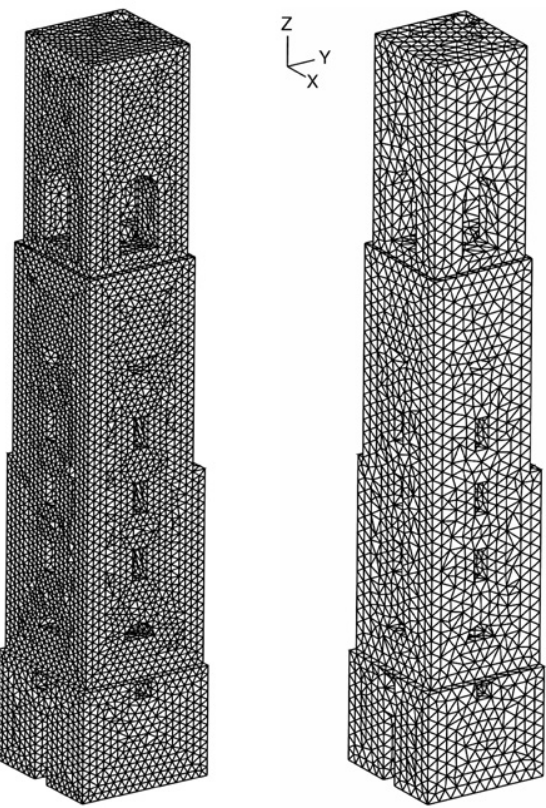

Fig. 3. Finite element meshes. 

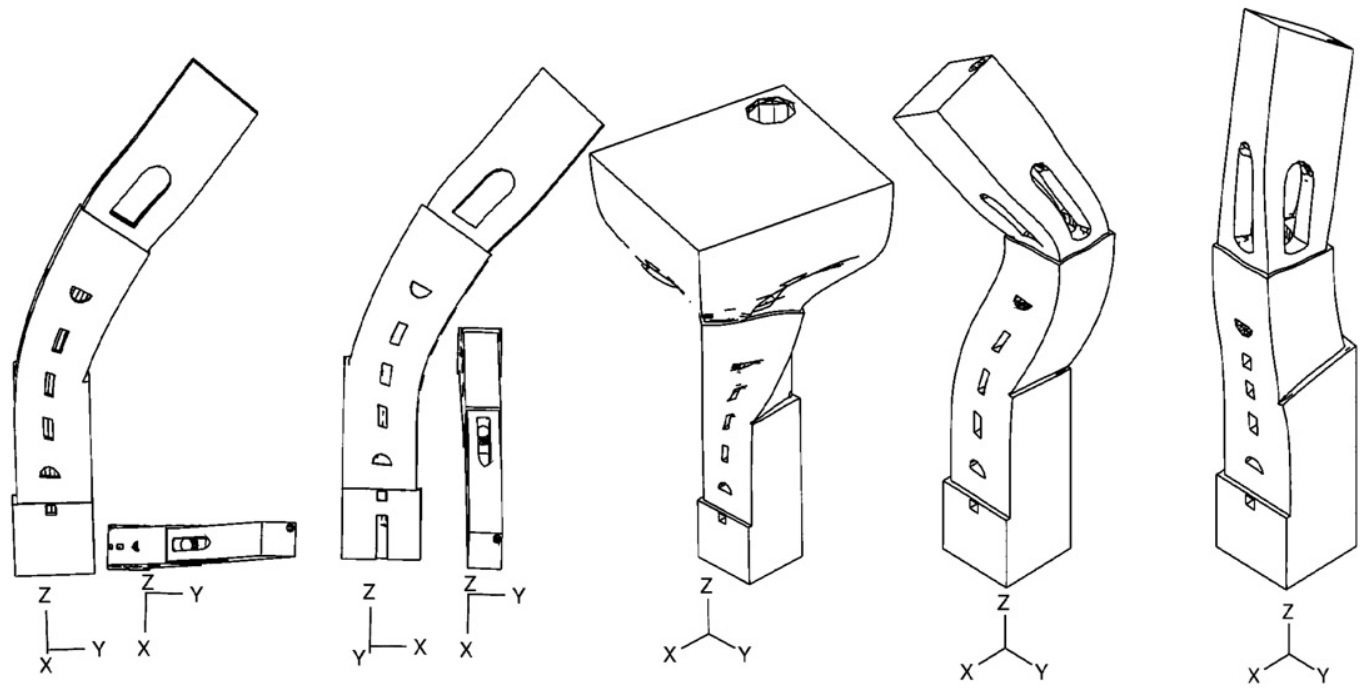

Fig. 4. First five vibration mode shapes and frequencies obtained with the initial numerical model.

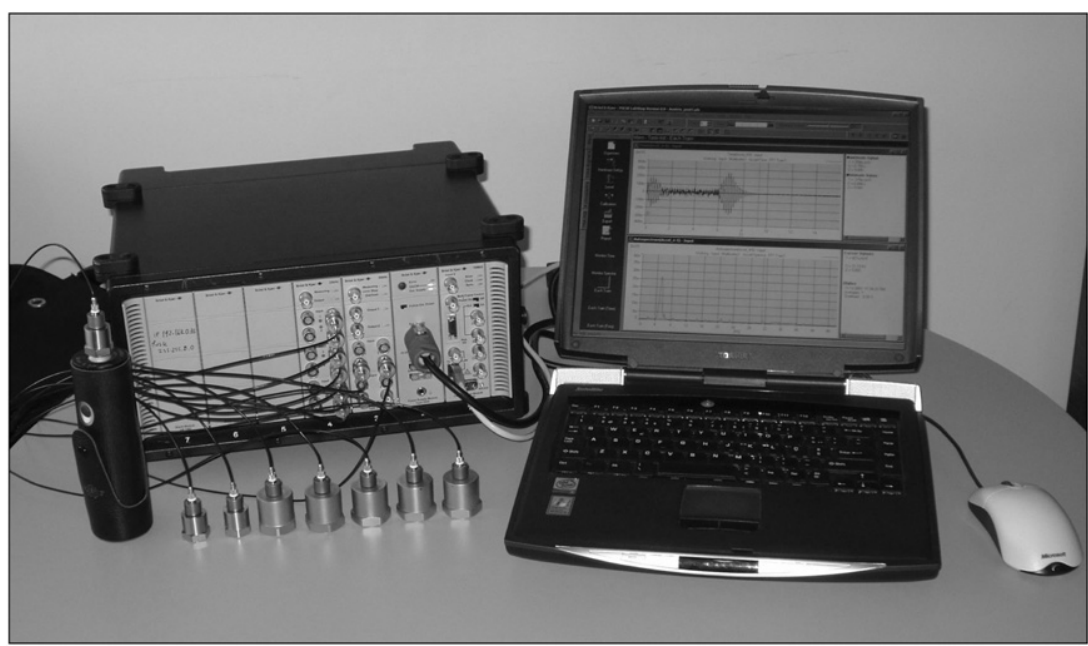

Fig. 5. Equipment used.

Table 1

Characteristics of the analysed time series and spectrums

\begin{tabular}{|c|c|c|c|c|c|}
\hline & Interval & Sample rate & Nyquist frequency & High-pass filter & Spectral window \\
\hline Time & $0.009766 \mathrm{~s}$ & $102.4 \mathrm{~Hz}$ & & & Superposition $2 / 3$ \\
\hline Frequency & $0.0125 \mathrm{~Hz}$ & & $51.2 \mathrm{~Hz}$ & $0.5 \mathrm{~Hz}$ & Hanning \\
\hline
\end{tabular}

this analysis were used to define the measurement points and, in a second stage, accelerations were measured on twenty points and directions, at different levels of the tower. Fig. 6 shows the respective localizations and the mesh used to visualize the mode shapes. In this stage, four transducers were kept at the terrace level, serving as reference, whilst the position of the remaining four was changed, using a total of four different locations: bell level; top semi-circular window; third rectangular door; and second rectangular door (see Fig. 6). In each setup, a continuous signal acquisition was carried out for approximately $45 \mathrm{~min}$. It should be noted that these measurements were executed on a particularly windy day and that, besides short periods of bell swaying and ambient vibration, the structure was not subjected to any other action.

The signal obtained was later treated by decimation and lowpass filtering, in order to reduce the dimension of the time series,
Table 2

Characteristics of the performed analysis

\begin{tabular}{ll}
\hline Configuration & Description \\
\hline Estimation of spectral density matrixes & \\
Frequency: number of lines & 4096 \\
Frequency: spacing & $0.0125 \mathrm{~Hz}$ \\
Superposition & $66.67 \%$ \\
Spectral window & Hanning \\
\hline Estimation of correlation functions & \\
Samples: number & 4096 \\
Correlation length & $39.99 \mathrm{~s}$ \\
Type of Estimator & Biased \\
\hline
\end{tabular}

keeping the capacity to compute spectra up to approximately $50 \mathrm{~Hz}$. The main characteristics concerning the time records and the frequency analysis are given in Tables 1 and 2 . 


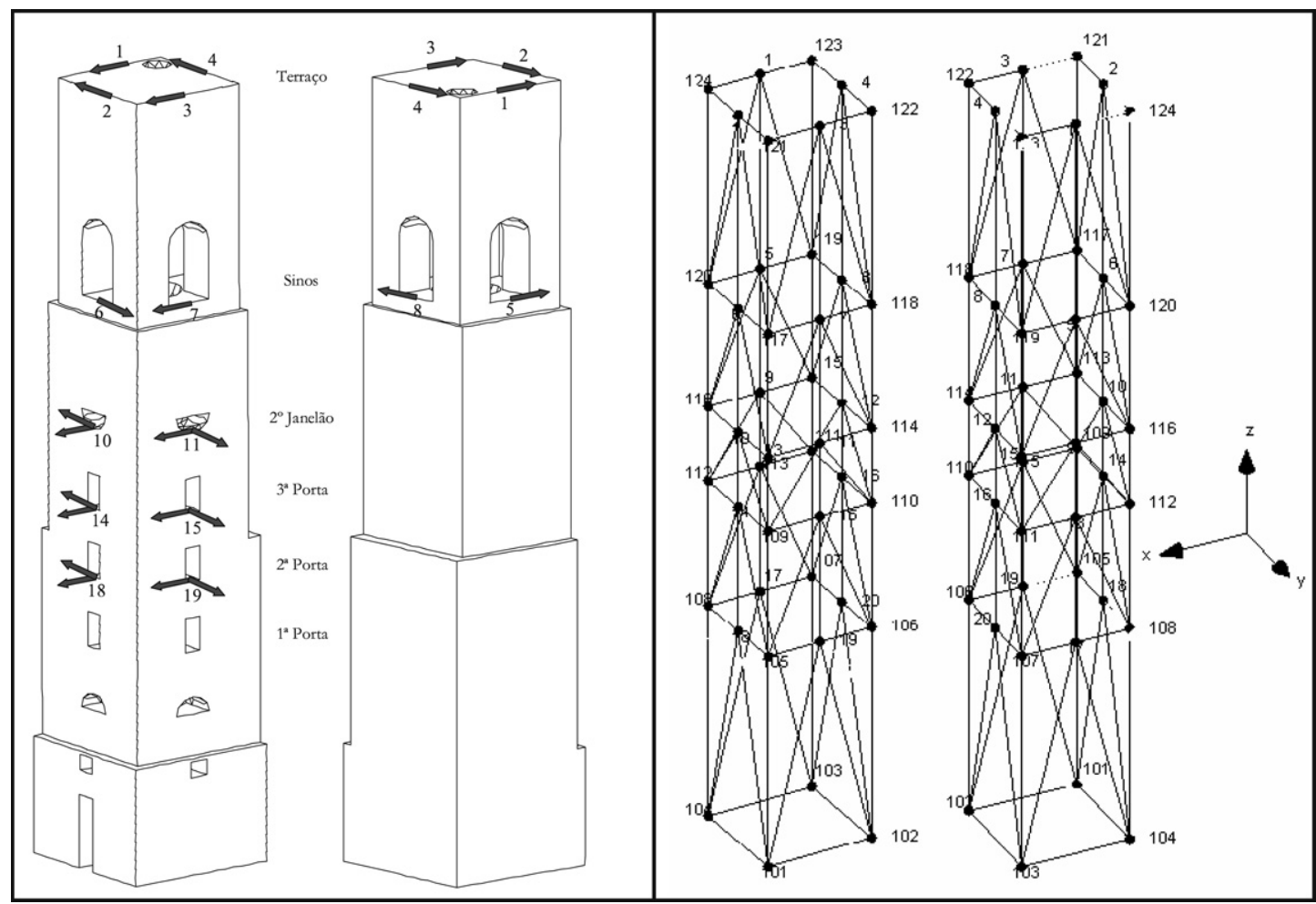

Fig. 6. Localization of accelerometers and mesh used in experimental modal identification.

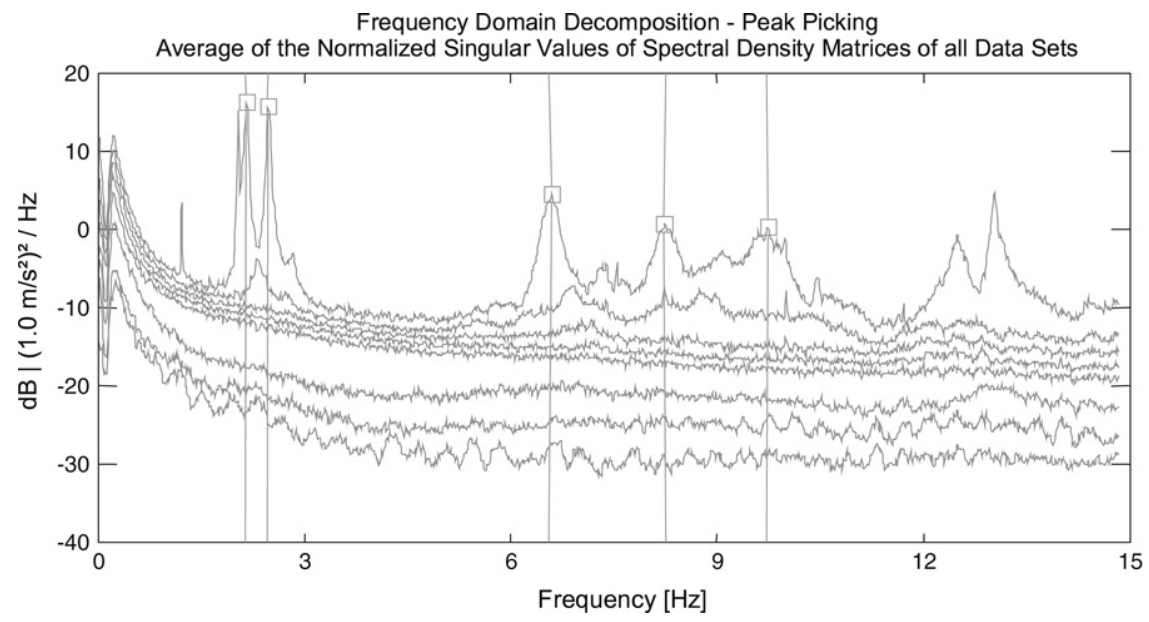

Fig. 7. Identification of spectral peaks.

The goal of the measurements consisted in identifying the first five natural frequencies and corresponding mode shapes, with the purpose of calibrating the finite element model. The power spectral densities for the set of performed measurements are presented in Fig. 7.

Since the swaying of the bells introduces vibration amplitudes with significant values when compared to those originated by ambient vibrations, namely those produced by the wind, spectral peaks are observed that do not correspond to any natural frequency but to the bells movement itself.

Fig. 8 shows the first five vibration mode shapes estimated from the recorded measurements and, in Table 3, the corresponding natural frequencies and modal damping values.

\subsection{Calibration and validation of the numerical model}

An expected non coincidence between measured values and values determined with the numerical model was observed.
Table 3

Natural frequencies and modal damping

\begin{tabular}{lll}
\hline Mode & Frequency $(\mathrm{Hz})$ & Damping $(\%)$ \\
\hline 1 & 2.133 & 0.61 \\
2 & 2.473 & 0.85 \\
3 & 6.557 & 1.53 \\
4 & 8.255 & 2.12 \\
$\mathbf{5}$ & 9.709 & 2.02 \\
\hline
\end{tabular}

Taking into account the uncertainty, previously referred to, in relation to some parameters with major influence in the dynamic behaviour of the tower, such as the localization of supports, the elastic characteristics of these and the Young's modulus and shear modulus of the walls, it was decided to adopt the following calibration methodology for the finite element model:

(1) Correction of the support conditions of the tower, by trial-anderror, until an acceptable resemblance was obtained between 


\section{$A R T C L E$ IN PRESS}
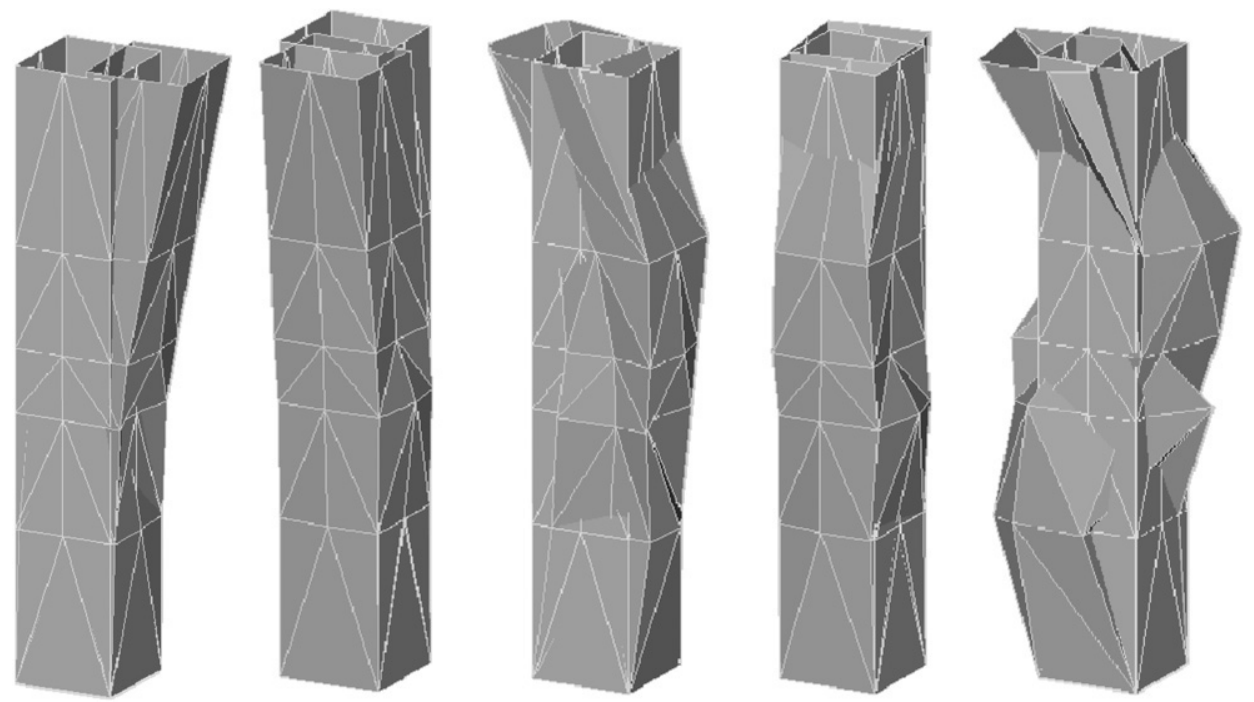

Fig. 8. First five vibration mode shapes estimated from the measurements.
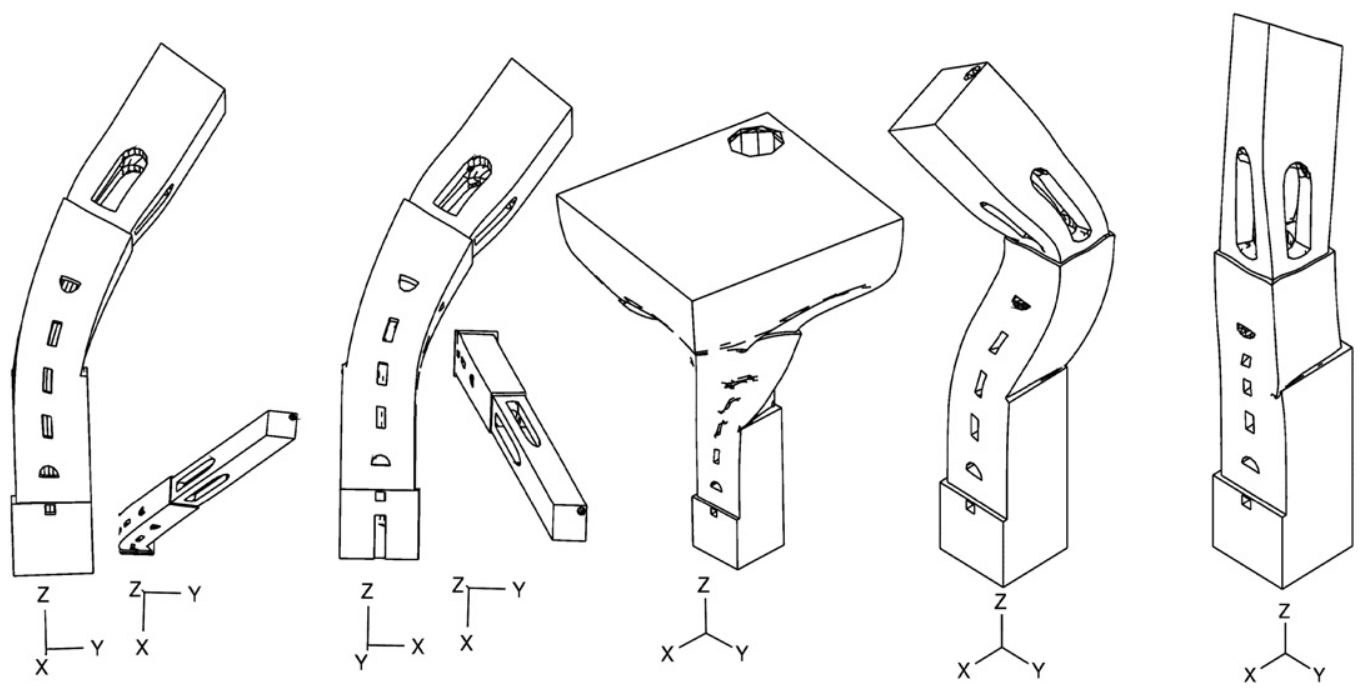

Fig. 9. First five vibration mode shapes and frequencies obtained with the numerical model with horizontal and vertical displacements of common walls restrained.

the first five vibration mode shapes as estimated from the readings and given by the numerical model;

(2) Calibration of the value of the equivalent Young's modulus and shear modulus assigned to the composite walls of the tower, by trial-and-error, until a suitable coincidence for the first five natural frequencies was registered, between measured values and values obtained with the finite element model.

Several models with different support conditions have been considered. Although the exhaustive presentation of these is not justified to illustrate the influence of this parameter on the dynamic behaviour of the tower, the vibration mode shapes and corresponding natural frequencies are presented, in Fig. 9, for a model which only differs from the original by having the vertical displacements restrained at the walls common to the tower and bounding volumes.

It must be highlighted that the first two vibration mode shapes are, for the original model, flexural modes in relation to N-S axis (1st mode) and W-E axis (2nd mode), see Fig. 4, which is in agreement with measured vibrations, see Fig. 8 . For the model formerly used as an example, the first two vibration mode shapes are also flexural modes but in relation to the diagonal axes of the tower cross section, instead of the above-mentioned axes.

Results of models with other possible different support conditions, corresponding to walls and slabs, were also analysed. Nevertheless, without a specific survey of the geometry and materials of the tower and adjacent areas of surrounding buildings and without soundings to characterize connections, it is not possible to estimate the accuracy of the support conditions of the adopted finite element model.

Once the support conditions of the numerical model to best reproduce the vibration mode shapes determined by vibration measurements had been corrected, the next step consisted in calibrating the Young's modulus and the shear modulus assigned to the tower walls in order to match the measured values of the natural frequencies. Again, the complete presentation of all models considered in the analysis carried out to calibrate this parameter is not justified. Nevertheless, to illustrate the influence of the latter, results are presented corresponding to three models that merely differ from each other in the value of the Young's modulus considered for the walls: 2 GPa, 5 GPa and 10 GPa- Fig. 10, Fig. 11 and Fig. 12, respectively. 

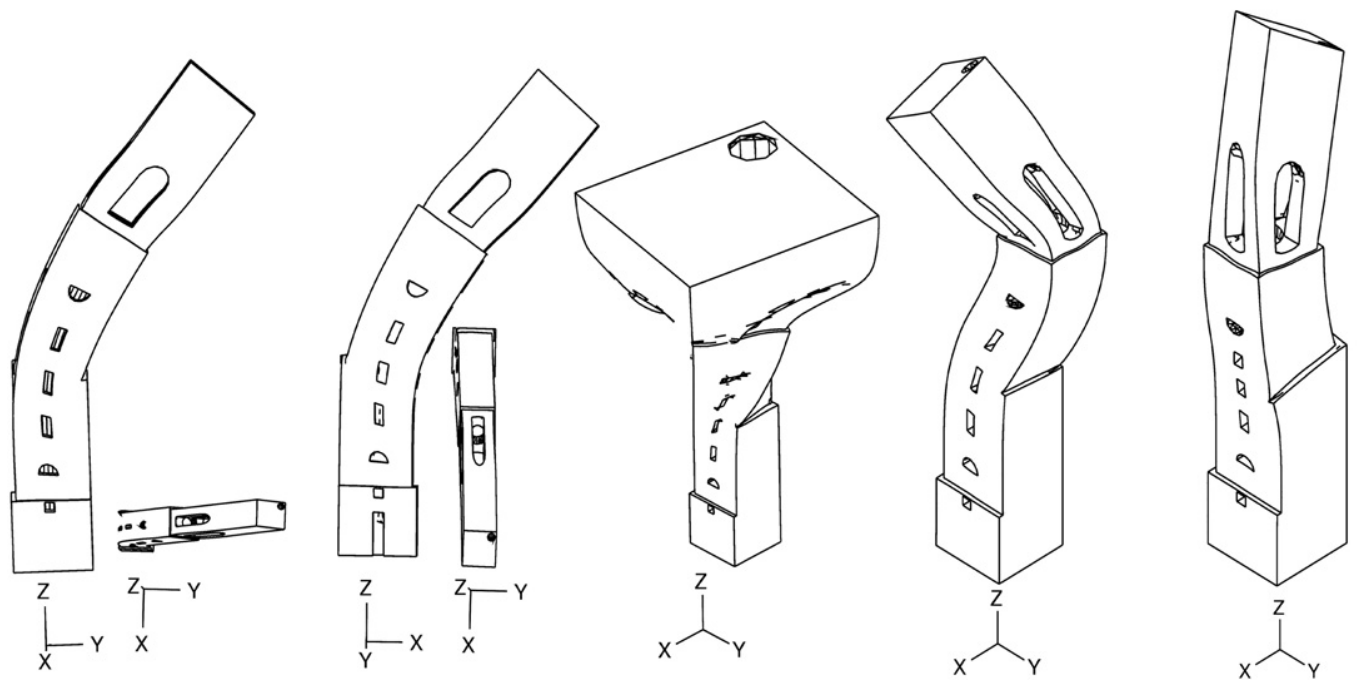

Fig. 10. First five vibration mode shapes and frequencies of the model with $E=2 \mathrm{GPa}$.

MODE 1, F 2.435

MODE 2, F 2.518

MODE 3, F 8.693

MODE 4, F 10.24

MODE 5, F 10.65
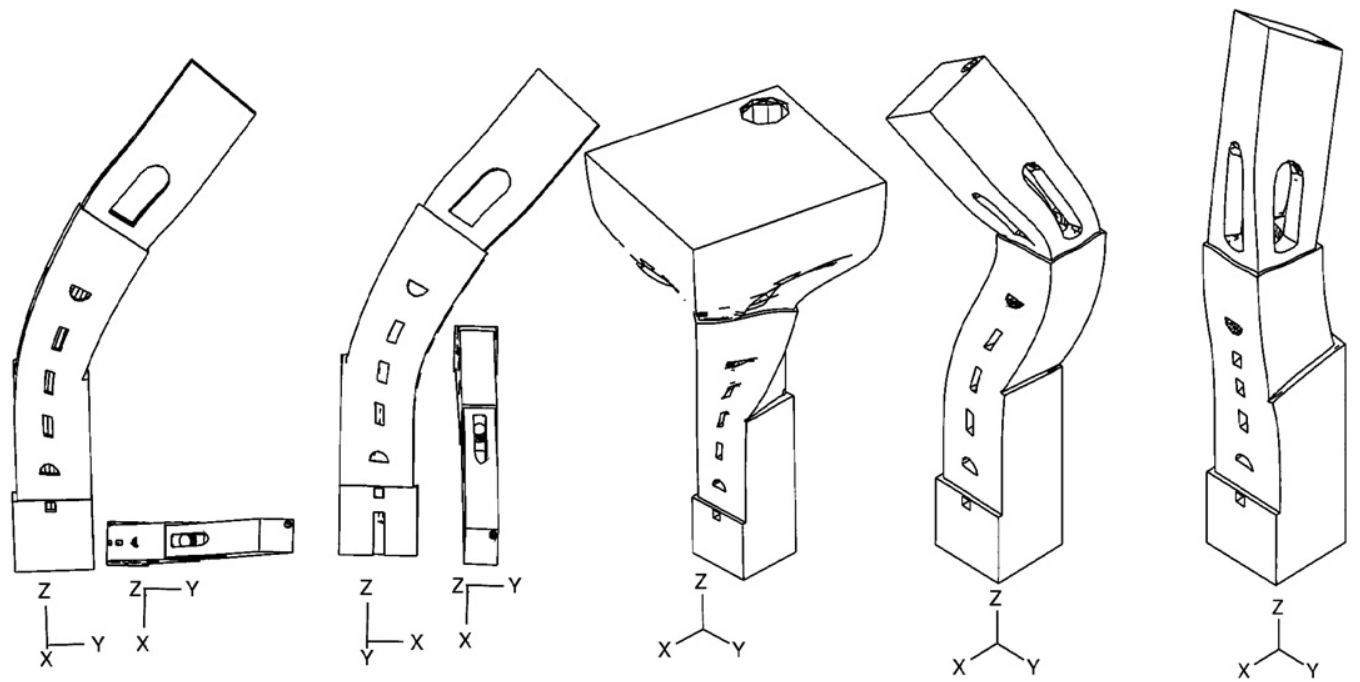

Fig. 11. First five vibration mode shapes and frequencies of the model with $E=5 \mathrm{GPa}$.

MODE 1, F 3.443

MODE 2, F 3.561

MODE 3, F 12.29

MODE 4, F 14.48

MODE 5, F 15.07
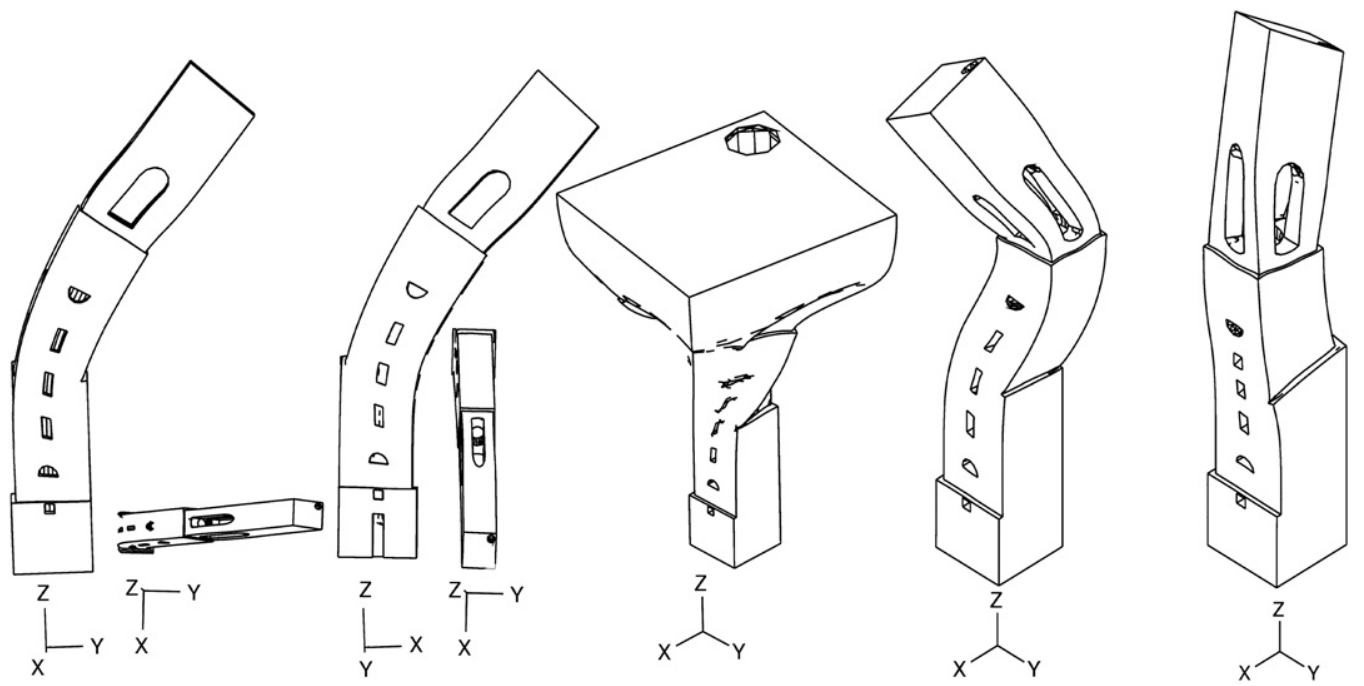

Fig. 12. First five vibration mode shapes and frequencies of the model with $E=10 \mathrm{GPa}$. 

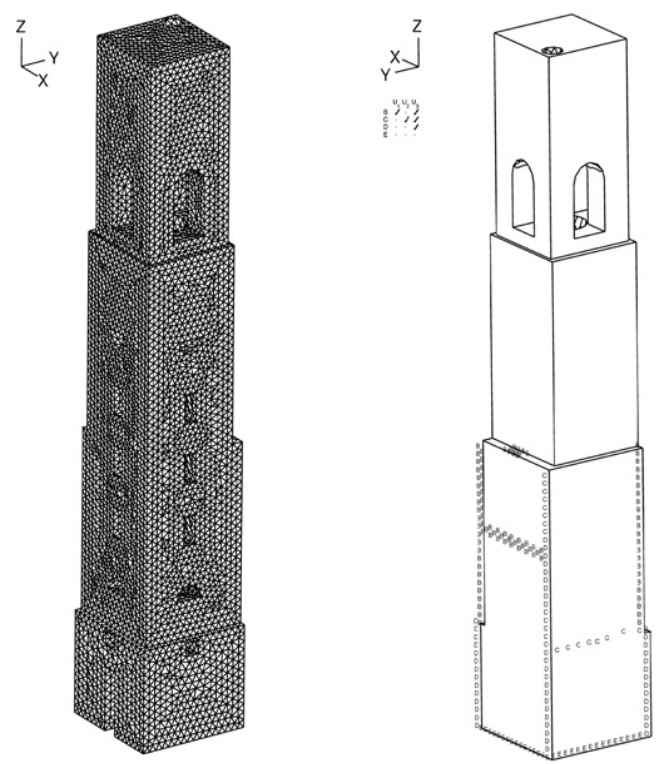

Fig. 13. Mesh and supports of the calibrated numerical model.

Associated with the increase in elasticity modulus and, as a consequence, in the tower stiffness, as expected, an increase in the values of each natural frequency is observed. Several results were analysed corresponding to models where different values of this parameter were assumed. It was also considered models where different values of the Young's modulus were assumed in different zones of the tower but this procedure was discarded since, without mechanical characterization of materials, it can lead to numerical results artificially close to measured values. It was decided to calibrate the finite element model using the same Young's modulus in order to numerically obtain the best possible approximation to the measured values of the natural frequencies, giving preference to the first two vibration modes.

Fig. 13 shows the mesh and supports of the finite element model of the University Tower. This was calibrated according to the exposed methodology, with all the difficulties inherent in the uncertainties referred to. A value of 5.5 GPa was adopted for Young's modulus and $0.34 \mathrm{GPa}$ for shear modulus, corresponding to $6 \%$ of the first. These results are in agreement with other published studies. For instance in [7] the modal identification of a $48 \mathrm{~m}$ high masonry tower built in the XVth century is described. Values of Young's modulus up to 5GPa and a shear modulus of

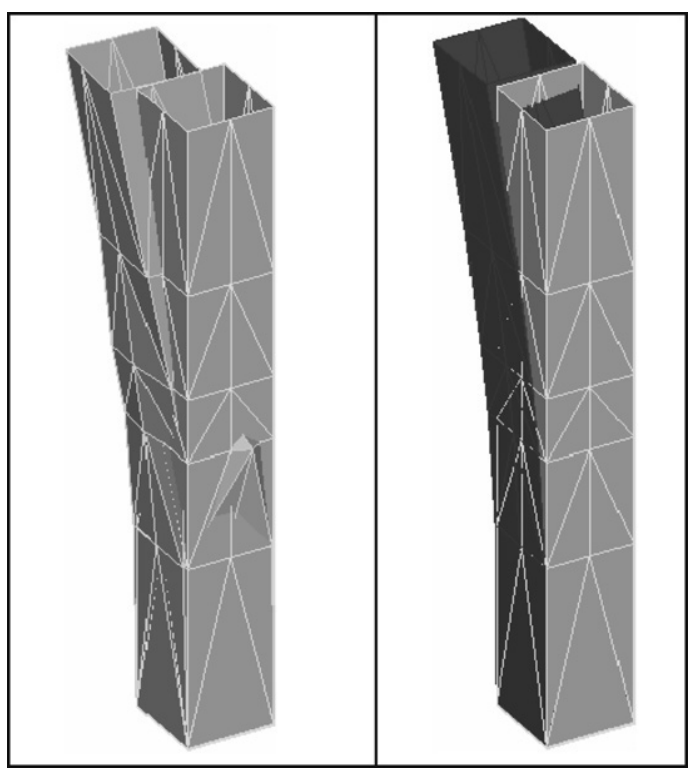

Fig. 15. Comparison between measured and computed 1st vibration mode shape.

\section{Table 4}

Comparison between measured and computed natural frequencies

\begin{tabular}{lllr}
\hline Mode & Measured frequency $(\mathrm{Hz})$ & Computed frequency $(\mathrm{Hz})$ & Error $(\%)$ \\
\hline 1 & 2.133 & 2.152 & -0.89 \\
2 & 2.473 & 2.403 & 2.83 \\
3 & 6.557 & 6.581 & -0.37 \\
4 & 8.255 & 8.160 & 1.15 \\
$\mathbf{5}$ & 9.709 & 9.583 & 1.30 \\
\hline
\end{tabular}

approximately $10 \%$ of the first are assumed. Furthermore, the authors state that the torsional modes of the tower could only be correctly identified after assuming an orthotropic material behaviour.

In Fig. 14 the first five vibration mode shapes and corresponding frequencies obtained with this model are presented. In Figs. 1519 each of the first five vibration mode shapes, obtained with the calibrated numerical model and with the measurements performed are presented. The correlation between the measured and calculated modes reveals a good match. When considering the natural frequencies (Table 4), a good approximation for the first five frequencies with a maximum error of $2.8 \%$ is also observed.
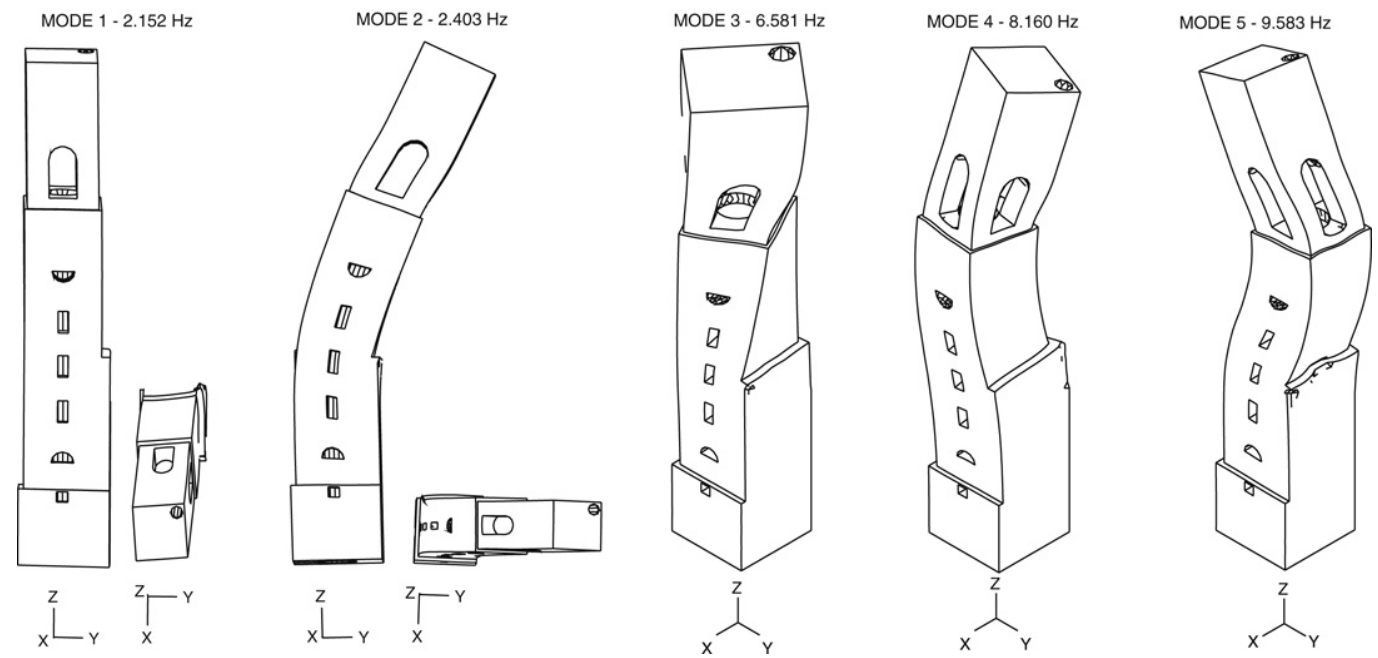

Fig. 14. First five vibration mode shapes and corresponding frequencies of the calibrated numerical model. 


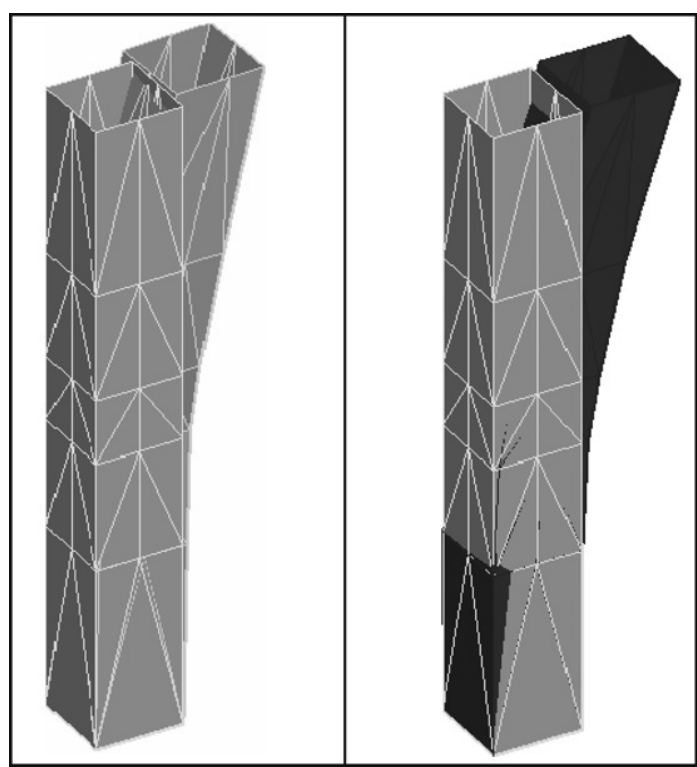

Fig. 16. Comparison between measured and computed 2nd vibration mode shape.

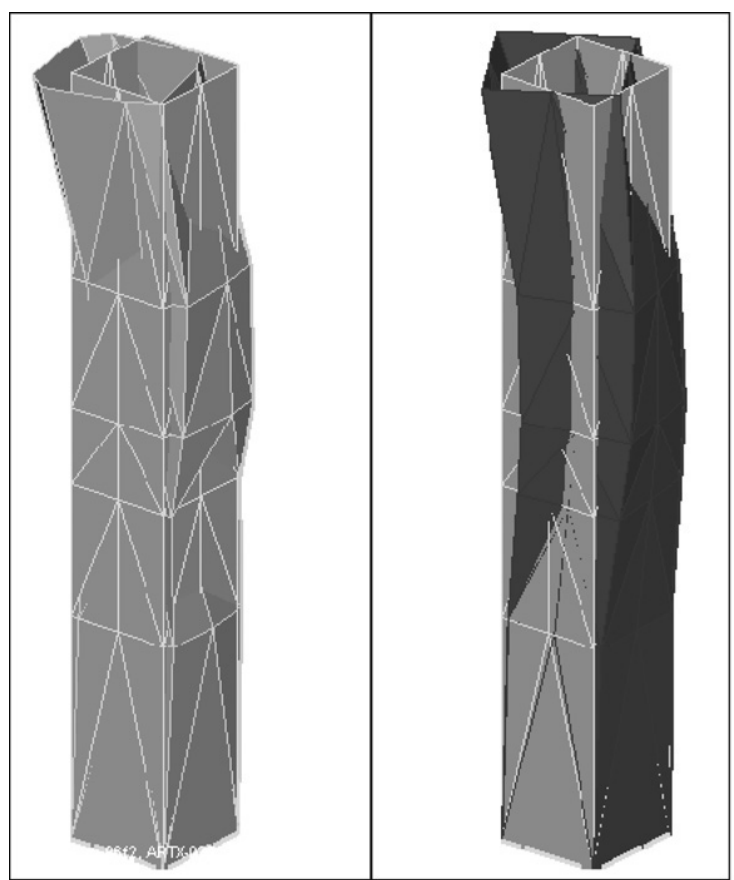

Fig. 17. Comparison between measured and computed 3rd vibration mode shape

\section{Discussion of results and conclusions}

A numerical model was developed using the finite element software ADINA, which was calibrated based on vibration measurements and modal analysis using modal extraction techniques in the frequency domain.

Despite the lack of knowledge or uncertainties in relation to parameters with influence on the structural behaviour, such as the support conditions and the mechanical characteristics of materials, analysis of the results allows the conclusion that the numerical model satisfactorily reproduces the dynamic response of the tower.

Furthermore, it can be stated that, from this analysis, there is not any evidence that the structural integrity of the tower is compromised. In fact, if inadmissibly lower values had been

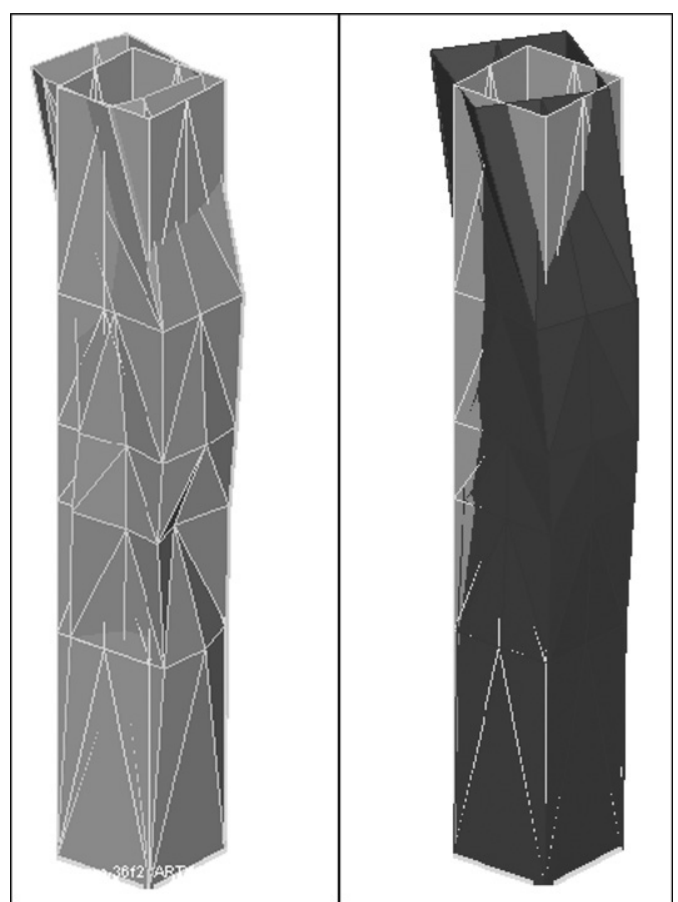

Fig. 18. Comparison between measured and computed 4th vibration mode shape.

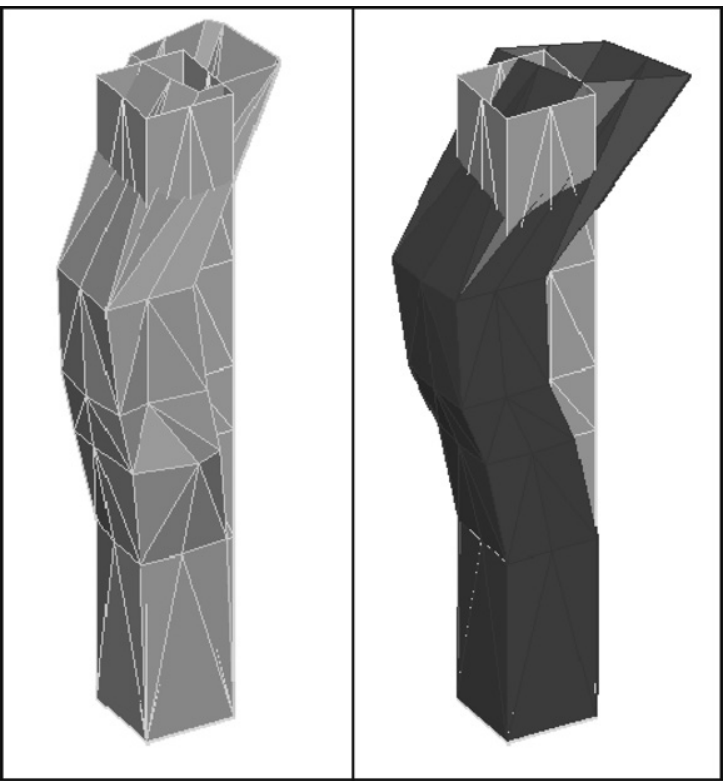

Fig. 19. Comparison between measured and computed 5th vibration mode shape.

obtained for the Young's modulus and/or shear modulus or if a different level of accuracy had been registered for one or more modal frequencies, one could have concluded that the integrity of the tower might be affected.

Since the planned restoration works include the correction of structural anomalies, such as cracks and out of place stone blocks, it was decided to carry out this intervention and to analyse afterwards, using the same methodology, correcting the numerical model if necessary and then to proceed with structural rehabilitation and/or strengthening operations.

Despite the unproven aspects of the structural assessment of the Tower of the University of Coimbra by modal identification, it was concluded that this is a reliable technique that can be used to rapidly establish most of the structural characteristics of this type 
of construction, corroborating the conclusions of similar studies [5]. However, it should be highlighted that this technique should be preferably used in combination with other on-site methods and/or laboratorial tests before claiming that it is a reliable judgment on the condition of a historical structure.

\section{References}

[1] Carpinteri A, Lacidogna G. Structural monitoring and integrity assessment of medieval towers. J Struct Eng 2006;132(11):1681-90.

[2] Modena C, Valluzzia M, Tongini Folli R, Binda L. Design choices and intervention techniques for repairing and strengthening of the Monza cathedral bell-tower. Construct Building Mater 2002;16:385-95
[3] Moschioni G. A virtual instrumentation system for measurements on the tallest medieval bell tower in Europe. IEEE Trans Instrumentation Measurement 2003; 52(3):693-702.

[4] Pimentel A. Home of knowledge. Ph.D. thesis in Humanities, area of History, speciality of History of Art, Faculty of Humanities of the University of Coimbra; 2003 [in Portuguese].

[5] Ramos L, Algeri F, Lourenço P, Modena C. Investigation techniques carried out on the Qutb Minar, New Delhi, India. In: Lourenço PB, Roca P, Modena C, Agrawal S, editors. Structural analysis of historical constructions. 2006.

[6] Roca P. The study and restoration of historical structures: From principles to practice. In: Lourenço PB, Roca P, Modena C, Agrawal S, editors. Structural analysis of historical constructions. 2006.

[7] Beneditini F, Gentile C. Ambient vibration testing and operational modal analysis of a masonry tower. In: Brincker R, Moller N, editors 2nd international modal analysis conference. 2007. p. 285-92. 